\title{
Technical Efficiency, Determinants and Risks of Watermelon Production in Bangladesh
}

\author{
Bishwajit Sarker ${ }^{1}$, Shankar Majumder ${ }^{2}$, Mst. Asma Khatun ${ }^{3}$ \\ ${ }^{1}$ (Sylhet Agricultural University, Sylhet, Bangladesh) \\ ${ }^{2}$ (Bangladesh Agricultural University, Mymensingh, Bangladesh) \\ ${ }_{3}^{3}$ (Bangladesh Agricultural University, Mymensingh, Bangladesh)
}

\begin{abstract}
The present study is conducted to examine the technical efficiency, identify factors causing inefficiency and assess farmer's perception on major sources of risk in producing watermelon in Bangladesh. In this purpose, a sample of 180 farmers has been selected by multistage stratified sampling technique from Patuakhali district due to the production intensity of watermelon coverage among various districts of Bangladesh. Data on farm-specific characteristics, output, input prices and costs during the production period of December, 2015 to April, 2016 have been collected from watermelon producers. A stochastic frontier production function model is used to analyze the technical efficiency of the farmers growing watermelon. Results obtained by fitting the model reveal that mean technical efficiency level is $86 \%$ indicating a scope for increasing average efficiency by 14\%.Natural calamity is the highest source of risk in watermelon production. The output elasticity corresponding to the significant $(p<0.05)$ coefficients of the inputs viz., human labour, amount of fertilizer used, irrigation cost and pesticide cost are 0.04, 2.99, 22.74 and 19.25, respectively. Technical inefficiency of the watermelon producer is reduced significantly $(p<0.05)$ as the farm size increases. Access to both training and microcredit exert a significant $(p<0.01)$ reduction in technical inefficiency of the farmers who produce watermelon. So, government and non-government organizations may take initiatives to improve watermelon productivity by providing training, and micro credit facility with low rate of interest to the farmers.
\end{abstract}

Keywords: Technical Efficiency, Stochastic Frontier Function Model, Risk, Watermelon, Bangladesh

\section{Introduction}

The economy of Bangladesh is traditionally agricultural. Most of the people of this country are directly or indirectly involved in agricultural activities for their livelihood. Agriculture has a great contribution to the Gross Domestic Product (GDP) of the country. Earlier more than 50\% of GDP came from this sector. When industrialization started the activities of the population started diversification towards different sectors. As a result, the contribution of the agriculture sector is slowly reducing and now reached 19\% share of GDP (Rabbany et al., 2013). The exponential increase of its population creates a pressure on silently decreasing cultivable land which necessitates thinking about efficient use of existing resources. Moreover, the available evidence suggests that farmers in the developing countries fail to exploit full potential of a technology and/or make allocative errors (Taylor and Shonkwiler, 1986; Ali and Flinn, 1989; Kalirajan and Shand, 1989; BravoUreta and Evenson, 1994; Banik, 1994; Shanmugam and Palanisami, 1994; Sharma and Datta, 1997; and Thomas and Sundaresan, 2000). Through efficiency gain in agricultural sector, the country not only will be able to save a significant chunk of foreign currency which in turn can be invested to develop agriculture but also to feed its growing population at low prices. Thus technical efficiency is a hot issue for food policy makers in the developing countries around the world. However, production of maximum amount of output with a given set of inputs and existing technology concerns with technical efficiency.

Bangladesh possesses suitable environment to produce rice, wheat, maize, jute, pulses, sugarcane, tea, oil seeds, potato etc. and also different kinds of fruits like as, mango, jackfruit, apple, watermelon etc. So, Bangladesh has a possibility to gain food sufficiency and superiority in the world by developing these crops and fruits. Watermelon is an important summer cash crop which has great demand in the domestic market. Its demand is increasing day by day but both acreage and production are decreasing. As an agricultural product, a major portion of income of the farmer comes from marketing and distribution of watermelon (Hoque et al., 2015). Watermelon is a delicious fruit in Bangladesh. It contains 90 percent water and it is very useful fruit during summer season to fulfill the demand of water. It bears vitamin A, B, C and minerals. (Rabbany et al., 2013).

A lot of published (with online) articles on technical efficiency in different crops, vegetables and fruits had been searched and reviewed. Majumder et al. (2016) analyzed Food security through increasing technical efficiency and reducing postharvest losses of rice production systems in Bangladesh. Hasnain et al. (2015), Rahman et al. (1999) and Islam et al. (2004) studied the technical efficiency of rice production in Bangladesh. 
Koirala et al. (2014) measured the technical efficiency of rice production and identified determinants of technical efficiency of rice farmers in Philippines. Haider et al. (2010) used the stochastic frontier approach to measure technical efficiency level of the agricultural farms of Khulna, Bangladesh. A study Hossain et al. (2008) carried out in three potato growing areas namely Munshiganj, Bogra and Jessore covering 75 potato growers to measure technical efficiency and economic performance of potato production. The study Bakh et al. (2005) and Rahman et al. (2002) was undertaken to measure the technical and allocative efficiency of wheat production in Bangladesh. Ibrahim et al. (2014) measured technical efficiency of watermelon in Borno State, Nigeria. The purpose of the study done by Kulekci (2010) examined the technical efficiency of farms producing sunflower in Erzurum, Turkey and to identify factors that might be causing inefficiency. But no research work has been done on technical efficiency of the watermelon producer in Bangladesh. For this reason, an attempt was made to conduct the present study.

\section{Objectives Of The Study}

The overall objective of the study is to find technical efficiency of the farm and risk in watermelon production and to explore the influences of farm specific socio-economic characteristics on the efficiency. The specific objectives can be pointed out as follows:

- to estimate specific and average technical efficiencies of the farm household in producing watermelon,

- to identify farm-specific factors which influence the technical efficiency of the farm household in cultivating watermelon,

- to estimate influencing risk factors of watermelon production and

- to suggest some policy option to optimum use of existing available resources for enhancing watermelon production.

\section{Materials And Methods}

Considering the intensity of watermelon production coverage among different districts of Bangladesh the study had been chosen Patuakhali district especially in sandy lands of coastal islands. A multi-stage stratified sampling design had been used for the selection of the watermelon growing farmers. In this study, Patuakhali district was specially chosen due to the production intensity of watermelon coverage among different districts of Bangladesh. Then three upazilas were selected from the district by using simple random sampling (SRS) technique. After selecting the upazilas one union from each selected upazila was selected randomly using SRS technique. Then, two villages from each union were selected by same technique. Finally, 30 watermelon growing farmers from each village were selected using multistage stratified sampling technique with equal allocation. The ultimate sample size was 180 under the present study. During the production period December, 2015 to April, 2016 data had been collected from watermelon producers.

Table 1: Selected study area from different regions of Patuakhali district

\begin{tabular}{|l|l|l|l|l|}
\hline District & Upazila & Union & Villages & No. of farmers \\
\hline \multirow{4}{*}{ Patuakhali } & & & Lunda & 30 \\
\cline { 4 - 5 } & Kalapara & Dhankhali & Debpur & 30 \\
\cline { 2 - 5 } & & & Boalia & 30 \\
\cline { 2 - 5 } & Galachipa & Ratandi & Itbaria & 30 \\
\cline { 2 - 5 } & & & Kachi-Bulia & 30 \\
\cline { 3 - 5 } & Rangabali & Rangabali & Fulkali & 30 \\
\hline Sample size & & & 180 \\
\hline
\end{tabular}

\subsection{Technical Efficiency}

\section{Methodology}

Farrell (1957) in his seminal paper illustrated the concept of technical efficiency. He said that it reflects the farm's ability to obtain maximal output from a given set of inputs. Production frontier represents the maximum attainable output at each input level. Hence, it reflects the current state of technology in the industry (Coelli et al., 2005). Aigner et al. (1977), Meeusen and Broeck (1977) and Battese and Corra (1977) proposed the model of stochastic production frontier as:

$\mathbf{Q}_{\mathrm{i}}=\mathbf{f}\left(\mathbf{X}_{\mathrm{i}}, \boldsymbol{\beta}\right) \exp \left(\mathbf{v}_{\mathbf{i}}-\mathbf{u}_{\mathrm{i}}\right)$

where $Q_{i}$ denotes the output of the $i-t h$ farm; $X_{i}=\left[\begin{array}{llll}1 & X_{1 i} & X_{2 i} \ldots & X_{p i}\end{array}\right]^{\prime}$ which is a $(p+1) \times 1$ vector of inputs of the $\mathrm{i}$-th farm; $\beta=\left[\begin{array}{llll}\beta_{0} & \beta_{1} & \beta_{2} \ldots & \beta_{\mathrm{p}}\end{array}\right]^{\prime}$ is a vector of unknown parameters; $\mathrm{v}_{\mathrm{i}}$ 's are the statistical noise. The $\mathrm{u}_{\mathrm{i}}$ 's are one-sided components (i.e., $\mathrm{u}_{\mathrm{i}} \geq 0$ ) which reflects technical efficiency relative to the stochastic frontier $Q_{i}=f\left(X_{i}, \beta\right) \exp \left(v_{i}\right)$. 
Various functional forms are available in the literature for the specification of stochastic frontier model. But, we choose Cobb-Douglas and Trans-log (transcendental logarithm) functions for their popularity. The general functional form of Cobb-Douglas and Trans-log can be presented as below:

Cobb-Douglus Model:

$$
\ln Q=\beta_{0}+\sum_{j=1}^{p} \beta_{j} \ln X_{j}
$$

Trans-log Model:

$$
\ln Q=\beta_{0}+\sum_{j=1}^{p} \beta_{j} \ln X_{j}+\frac{1}{2} \sum_{j=1}^{p} \sum_{k=1}^{p} \beta_{j k} \ln X_{j} \ln X_{k}
$$

where $\beta_{\mathrm{jk}}=\beta_{\mathrm{kj}}$ for all $\mathrm{j}$ and $\mathrm{k}$;

$\mathrm{Q}$ represents the quantity of watermelon (in Piece);

$\mathrm{X}_{1}$ is the amount of seed used (in kilogram);

$\mathrm{X}_{2}$ is the total labour input (man-day) by family and hired labourers in the growing and harvesting of watermelon;

$\mathrm{X}_{3}$ is the pesticide cost (in taka);

$\mathrm{X}_{4}$ is the tillage cost (in taka);

$\mathrm{X}_{5}$ is the irrigation cost (in taka);

$\mathrm{X}_{6}$ is the manure (in tonne);

$\mathrm{X}_{7}$ is the total amount of fertilizer applied (viz. Urea, TSP, MP etc. in kilogram);

$\beta_{0}, \beta_{\mathrm{j}}$ 's, $\beta_{\mathrm{jk}}$ 's are the unknown parameters to be estimated;

Vi Random error, assumed to be independently and identically distributed as $\mathrm{N}\left(0, \sigma_{\mathrm{v}}{ }^{2}\right)$

Ui One-sided inefficiency component, assumed to be non-negative truncations of $\mathrm{N}\left(0, \sigma_{\mathrm{v}}{ }^{2}\right)$ distribution (i.e., a half normal distribution). We applied Cobb-Douglas and translog production functions to assess the technical efficiency. The Cobb-Douglas production model was tested against the translog model and the null hypothesis was "The production frontier follows Cobb-Douglas form, that is, all the effects of square and interaction terms in the translog model are zero i.e.H0 : $\beta \mathrm{jk}=0$ ". The above hypothesis was tested using the likelihood ratio test statistic which is defined as $\lambda=-2\left\{\ln \left[\mathrm{L}\left(\mathrm{H}_{0}\right)-\ln \left[\mathrm{L}\left(\mathrm{H}_{1}\right)\right\}\right.\right.$;

$\mathrm{L}\left(\mathrm{H}_{0}\right)$ and $\mathrm{L}\left(\mathrm{H}_{1}\right)$ indicate the likelihood values under the null and alternative hypotheses that correspond to the Cobb- Douglas model and translog model respectively. The test statistic $\lambda$ had an approximately chisquare distribution with degrees of freedom equal to the difference between the number of parameters involved in $\mathrm{H}_{0}$ and $\mathrm{H}_{1}$. According to this result, a trans-log stochastic production frontier model is appropriate for fitting the watermelon production data.

Another test which is also based on generalized likelihood ratio is carried out to check whether the trans-log stochastic production frontier model follows the linear homogeneity constraint (i.e. constant returns to scale) or not. According to this test, it is found that a homogeneity constrained trans-log stochastic production frontier model is the best fit to the watermelon production data.

The technical efficiency of the i-th farm can be written as: $\mathbf{T E}_{\mathbf{i}}=\mathbf{Q}_{\mathbf{i}} / \mathbf{Q}_{\mathbf{i}}$

where $\mathrm{Q}_{\mathrm{i}}$ denotes realized or observed output of the $\mathrm{i}$-th farm for a given input level and technology, $\mathrm{Q}_{\mathrm{i}}{ }^{*}$ denotes the maximal attainable or production frontier output of $\mathrm{i}$-th farm at the same input level and technology.

The model for the technical inefficiency effects in the stochastic frontier of equation (2) and (3) is defined (Battese and Coelli, 1995) and Kulekci (2010) as follows:

$\mathbf{u}_{\mathrm{i}}=\boldsymbol{\delta}_{\mathbf{0}}+\mathbf{Z}_{\mathrm{i}} \boldsymbol{\delta}+\mathbf{w}_{\mathrm{i}}$

Where $Z_{1}=$ Farm size which is the summation of homestead area, pond area, total cultivable area and fallow land owned by the watermelon growing farmer (in decimal);

$\mathrm{Z}_{2}=$ Age of the watermelon growing farmer (in year);

$\mathrm{Z}_{3}=$ Education of the watermelon growing famer (in year of schooling);

$\mathrm{Z}_{4}=$ Dummy variable for extension contact received by the watermelon growing farmer ( 1 for yes and 0 , otherwise);

$\mathrm{Z}_{5}=$ Experience on farming of the farmer (in year);

$\mathrm{Z}_{6}=$ Dummy variable for watching and/or listening agriculture related programmes on TV and/or radio (1 for yes and 0 , otherwise);

$\mathrm{Z}_{7}=$ Dummy variable for micro credit taken from any source (e.g., relatives, friends, NGOs, Banks, etc.) only for cultivating watermelon ( 1 for yes and 0 , otherwise);

$\mathrm{Z}_{8}=$ Dummy variable for profession ( 1 for on farm and 0 for off farm);

$Z_{9}=$ Dummy variable for training on farming participated by the watermelon growing famer ( 1 for yes and 0 , otherwise); 
$\mathrm{Z}_{10}=$ Dummy variable for mode of ownership ( 1 for own land and 0 for otherwise);

$\delta_{0, \ldots,} \delta_{10}$ are unknown parameters to be estimated; and

$\mathrm{w}_{\mathrm{i}}$ 's are random error that are defined by the truncation of the normal distribution with zero mean and variance, $\sigma_{\mathrm{w}}{ }^{2}$, such that the point of truncation is $-Z_{\mathrm{i}} \delta$, i.e., $\mathrm{w}_{\mathrm{i}}>-\mathrm{Z}_{\mathrm{i}} \delta$. These assumptions are consistent with $\mathrm{u}_{\mathrm{i}}$ being a nonnegative truncation of the $\mathrm{N}\left(\mathrm{Z}_{\mathrm{i}} \delta, \sigma_{\mathrm{u}}^{2}\right)$-distribution.

The technical inefficiency of an individual farmer is defined as

Technical inefficiency $=1-\left(\exp -\mathrm{U}_{\mathrm{i}}\right)=1-($ Observed output $/$ Maximum possible output $)$

The parameters involved in models (2), (3) and (5), together with the variance parameters which are expressed in terms $\sigma^{2}=\sigma_{\mathrm{u}}{ }^{2}+\sigma_{\mathrm{v}}{ }^{2}$ and $\gamma=\sigma_{\mathrm{u}}{ }^{2} / \sigma_{\mathrm{v}}{ }^{2}$ (where $\gamma$ lies between 0 and 1) are estimated by the maximum likelihood method using the computer program Frontier Version 4.1 (Coelli 1996).

Individual significance tests of the parameters were done by using t-tests and the overall significance tests of the parameters in the frontier production functions and in the inefficiency effect models were performed using generalized likelihood-ratio (LR) tests. The null hypotheses "There is no inefficiency effect i.e. $\mathrm{H}_{0}: \gamma=\delta_{0}$ $=\delta_{1}=. .=\delta_{10}=0$ ", "The inefficiency effects are not stochastic. i.e $\mathrm{H}_{0}: \gamma=0$ " and "The coefficients of the factors in the inefficiency effect model are zero i.e. $\mathrm{H}_{0}: \delta_{1}=\delta_{2}=\ldots=\delta_{10}=0$ " were tested using the test statistic stated in equation (5). All the tests of hypotheses were conducted at the $5 \%$ level of significance. The critical value of the test statistic was taken from Kodde and Palm (1986). If the calculated value of the test statistic is greater than or equal to its corresponding critical value, the null hypothesis was rejected.

\subsection{Output Elasticity}

Output elasticity refers to the percentage change in output due to one percentage change in input for a given technology. In case of Cobb-Douglas type of production function like (2), the $\beta_{j}$ 's $(j \neq 0)$ represent the output elasticity coefficients. But in case of trans-log production function like (3), the output elasticity coefficient for $\mathrm{j}$-th input is computed by the following formula (Kalirajan and Flinn, 1983)

$$
\varepsilon_{j}=\frac{\partial \ln Q}{\partial \ln X_{j}}=\beta_{j}+\beta_{j j} \ln X_{j}+\sum_{j=1}^{7} \sum_{\substack{k=1 \\ j \neq k}}^{7} \beta_{j k} \ln X_{k}
$$

\subsection{Risk measurement}

Kruskal-Wallis ranking analysis was used to assess farmer's perception on major sources of risk in watermelon farming (objective 3 of the study). This tool was used to measure the responses gathered from farmer's perception on sources of risks associated with watermelon farming. Fakayode et al. (2012) used Kruskal-Wallis one way analysis of variance (ANOVA) by ranks to assign priorities to identify constraints to Apiculture.

The equation for estimating the ranks is outlined as below:

$\mathrm{H}=\frac{12}{\mathrm{~N}+1} \sum_{\mathrm{i}=1}^{\mathrm{n}_{\mathrm{i}}} \frac{1}{\mathrm{n}_{\mathrm{i}}} \frac{\left[\mathrm{R}_{\mathrm{i}}-\mathrm{n}_{\mathrm{i}}(\mathrm{N}+1)^{2}\right]}{2}$

Where $R_{i}$, is the sum of the ranks assigned to observation in the ith sample and $\frac{n_{i}(N+1)}{2}$, the expected sum of ranks for the ith treatment (Wayne, 1990).

\subsection{Description of Data}

\section{Results And Description}

In the present study, data on output and inputs are used to estimate farm level technical efficiency of watermelon production. Before estimation, some properties of data such as mean, standard error (mean) are calculated. The properties of data are shown in Table 2. It is seen that the mean area under watermelon cultivation is 173.76 decimals in the study area. Again, the average output, human labour, seed, fertilizer, manure, irrigation cost, tillage cost, and pesticide cost are 64.988 piece, 0.103 man-day, $0.004 \mathrm{~kg}, 8.132 \mathrm{~kg}$, 0.001 tonne, Tk. 61.925 , Tk. 97.624, Tk. 52.426 respectively, of sample farmers.

Table 2: Different characteristic of input resources of watermelon cultivation

\begin{tabular}{|l|l|l|}
\hline Input & Mean value & Standard Error (Mean) \\
\hline Area (decimal) & 173.765 & 11.5315 \\
\hline Watermelon output (piece/decimal) & 64.988 & 0.1232 \\
\hline Human labour (man-day/decimal) & 0.103 & 0.0044 \\
\hline Seed (kg/decimal) & 0.004 & 0.0002 \\
\hline Fertilizer (kg/decimal) & 8.132 & 0.0050 \\
\hline Manure (tonne/decimal) & 0.001 & 0.0002 \\
\hline Irrigation cost (taka/decimal) & 61.925 & 0.0412 \\
\hline Tillage cost (taka/decimal) & 97.624 & 34.7339 \\
\hline Pesticide cost (taka/decimal) & 52.426 & 0.4062 \\
\hline
\end{tabular}

Source: Authors own calculation 
The maximum likelihood estimates of the parameters in the tans-log production frontier model and the technical inefficiency effect model, for watermelon is presented in Table 3. These empirical results say that there is a scope for increasing watermelon production by increasing human labour and irrigation, since the coefficients of these parameters are positive and significant $(\mathrm{p}<0.01)$. But, a negative and significant $(\mathrm{p}<0.01)$ coefficient indicates that there is no opportunity of increasing the production of watermelon by enhancing pesticide cost and fertilizer cost.

An important result for the present study from Table 3 is that the variance ratio parameter $\gamma$ is very large, closed to one, given the interval within which it lies, and differ significantly $(\mathrm{p}<0.01)$ from zero. This implies that about 98.7 per cent of the difference between the observed output and the maximum production frontier output is caused by differences in farmers' levels of technical efficiency as opposed to the conventional random variability.

Table 3: Maximum likelihood estimates of the parameters of the Trans-log stochastic production frontier model for watermelon

\begin{tabular}{|c|c|c|c|}
\hline Variable & Parameter & Coefficient & Standard Error \\
\hline Intercept & $\beta_{0}$ & $10.51 * *$ & 3.62 \\
\hline Seed (kilogram) & $\beta_{1}$ & 1.130 & 0.670 \\
\hline Human labour (man-days) & $\beta_{2}$ & $1.69 *$ & 0.950 \\
\hline Pesticide cost (taka) & $\beta_{3}$ & $-0.80 *$ & 0.623 \\
\hline Tillage cost (taka) & $\beta_{4}$ & -0.73 & 0.414 \\
\hline Irrigation cost (taka) & $\beta_{5}$ & $2.40 *$ & 0.43 \\
\hline Manure (tonne) & $\beta_{6}$ & 9.57 & 0.192 \\
\hline Amount of fertilizer (kg) & $\beta_{7}$ & $-.029 *$ & 0.412 \\
\hline Seed $\times$ Human labour & $\beta_{12}$ & $-.18 * *$ & 0.09 \\
\hline Seed $\times$ Pesticide cost & $\beta_{13}$ & $-0.09 * *$ & 0.04 \\
\hline Seed $\times$ Tillage cost & $\beta_{14}$ & $.05 * *$ & 0.05 \\
\hline Seed $\times$ Irrigation cost & $\beta_{15}$ & $0.155^{* *} *$ & 0.059 \\
\hline Seed $\times$ Manure & $\beta_{16}$ & 0.01 & 0.02 \\
\hline Seed $\times$ Fertilizer cost & $\beta_{17}$ & -.06 & 0.05 \\
\hline Human labour $\times$ Pesticide cost & $\beta_{23}$ & -.11 & 0.06 \\
\hline Human labour $\times$ Tillage cost & $\beta_{24}$ & 0.03 & 0.04 \\
\hline Human labour $\times$ Irrigation cost & $\beta_{25}$ & .15 & 0.08 \\
\hline Human labour $\times$ Manure & $\beta_{26}$ & 0.01 & 0.02 \\
\hline Human labour $\times$ Fertilizer cost & $\beta_{27}$ & $-.33 * *$ & 0.06 \\
\hline Pesticide cost $\times$ Tillage cost & $\beta_{34}$ & $0.12 * *$ & 0.03 \\
\hline Pesticide cost $\times$ Irrigation cost & $\beta_{35}$ & -.03 & 0.03 \\
\hline Pesticide cost $\times$ Manure & $\beta_{36}$ & -.01 & 0.01 \\
\hline Pesticide cost $\times$ Fertilizer cost & $\beta_{37}$ & -0.008 & 0.02 \\
\hline Tillage cost $\times$ Irrigation cost & $\beta_{45}$ & $-.24 * *$ & 0.04 \\
\hline Tillage cost $\times$ Manure & $\beta_{46}$ & .33 & 0.01 \\
\hline Tillage cost $\times$ Fertilizer cost & $\beta_{47}$ & $.37 * *$ & 0.04 \\
\hline Irrigation cost $\times$ Manure & $\beta_{56}$ & -0.02 & 0.01 \\
\hline Irrigation $\cos t \times$ Fertilizer cost & $\beta_{57}$ & $0.002 * *$ & 0.03 \\
\hline Manure $\times$ Fertilizer cost & $\beta_{67}$ & $-0.03^{*}$ & 0.01 \\
\hline \multirow[t]{2}{*}{ Variance parameters } & $\sigma^{2}$ & $0.811^{* *}$ & 0.17 \\
\hline & $\gamma$ & $0.987 * *$ & 0.003 \\
\hline Log-likelihood value & & 52.3 & \\
\hline
\end{tabular}

Output elasticity coefficient with respect to individual input is computed using the frontier estimates (Table 4) and the mean values of inputs. The output elasticity coefficients are exhibited in Table 4 only for significant coefficients of the inputs. All the output elasticity coefficients are elastic. For instance, the output will increase (or decrease) by $0.04,2.99,22.74$ and 19.25 per cent (on an average) for one percent increase (or decrease) in human labour, amount of fertilizer used, irrigation cost and pesticide cost, respectively holding other factors constant.

Table 4: Frontier production elasticity of human labour, amount of fertilizer, irrigation cost and pesticide cost in producing watermelon

\begin{tabular}{|l|l|}
\hline Input & Output elasticity $^{\mathrm{a}}$ \\
\hline Human labour & 0.04 \\
\hline Amount of Fertilizer & 2.99 \\
\hline Irrigation cost & 22.74 \\
Pesticide cost & 19.25 \\
\hline${ }^{\mathrm{a}}$ Computed using output elasticity formula at mean level of input application given in Table 2 \\
\hline
\end{tabular}


The farm-specific technical efficiency of the individual watermelon growing farmers is estimated and reported in Table 5. These results reveal wide variation in the levels of technical efficiencies across the sample farms, ranging from 0.26 to 0.98 . Around 90 per cent of the sample participants have obtained output in the neighborhood of the maximum output estimated through the frontier. Only $10 \%$ farms have moderate or weak technical efficiency levels.

Table 5: Frequency distribution of the farm-specific technical efficiencies' of the farmers under watermelon production and the descriptive statistics

\begin{tabular}{|l|l|l|}
\hline Technical Efficiency (per cent) & Number of farm & Percentage \\
\hline $20-30$ & 1 & 0.56 \\
\hline $30-40$ & 2 & 1.11 \\
\hline $40-50$ & 3 & 1.67 \\
\hline $50-60$ & 2 & 1.11 \\
\hline $60-70$ & 4 & 2.22 \\
\hline $70-80$ & 6 & 3.33 \\
\hline $80-90$ & 68 & 37.78 \\
\hline $90-100$ & 94 & 52.22 \\
\hline Total & 180 & 100.00 \\
\hline Mean & 86 & \\
\hline Minimum & 26 & \\
\hline Maximum & 98 & \\
\hline
\end{tabular}

The estimated coefficients of the inefficiency effect model are of particular interest in this study. The findings of the inefficiency effect model are presented in Table 6 . The farm size coefficient is negatively significant $(\mathrm{p}<0.01)$, which indicates that inefficiency of the watermelon producer decreases as the farm size increases. The coefficient of micro credit is negatively significant $(p<0.01)$, implies that more access to micro credit will lead to less inefficiency in growing watermelon. The importance of micro credit in agricultural farming was explored by Binam et al. (2004) and Bozoglu and Ceyhan (2007). They reported that the shortage of working capital due to high input costs positively affected the farmer's level of technical inefficiency. That is, the more the shortage of working capital, the more the inefficiency of the farmer. The significant $(p<0.01)$ positive impact of age on inefficiency level indicates that older farmers are more inefficient than younger ones.

Table 6: Estimates of the parameters corresponding to the farm-specific characteristics (determinants) obtained by fitting the technical inefficiency effect model to watermelon data

\begin{tabular}{|c|c|c|c|}
\hline Variable & Parameter & Coefficient & Standard Error \\
\hline Intercept & $\delta_{0}$ & -3.49 & 2.42 \\
\hline Farm size (decimal) & $\delta_{1}$ & $-.004 * *$ & .0006 \\
\hline Age (years) & $\delta_{2}$ & $.03 *$ & .001 \\
\hline Education (years of schooling) & $\delta_{3}$ & .09 & .09 \\
\hline Extension contact $($ yes $=1 ;$ no $=0)$ & $\delta_{4}$ & $.57 *$ & .25 \\
\hline Experience (years) & $\delta_{5}$ & -.01 & .06 \\
\hline $\begin{array}{l}\text { Watching or listening Agricultural programme on TV and/or } \\
\text { Radio }(\text { yes }=1 ; \text { no }=0 \text { ) }\end{array}$ & $\delta_{6}$ & -.13 & .261 \\
\hline Micro credit $($ yes $=1 ;$ no $=0)$ & $\delta_{7}$ & $-.02 * *$ & .260 \\
\hline Profession $($ on farm = 1; off farm = 0) & $\delta_{8}$ & -.47 & .39 \\
\hline Training $($ yes $=1 ;$ no $=0)$ & $\delta_{9}$ & $-.01 * *$ & .407 \\
\hline Mode of ownership (own land =1; others $=0$ ) & $\delta_{10}$ & -.11 & .193 \\
\hline
\end{tabular}

$* *$ and $*$ indicate significant at $\mathrm{p}<0.01$ and $\mathrm{p}<0.05$ respectively.

In this study, training significantly $(\mathrm{p}<0.01)$ reduces technical inefficiency of the watermelon growing farmers while extension contract exhibits a significant $(\mathrm{p}<0.05)$ positive association with the inefficiency effects of the farmers growing watermelon. Bala et al. (2009) reported that extension work consists of two forms: (i) extension by advice, i.e., extension contact and (ii) extension by training, i.e., training. They also reported that training is superior to advice and there is no alternative to training for transfer of technology. Besides Alam et al. (2005) reported that the extension did not reduce the technical inefficiency significantly. The farmers who received training provided by extension department were more efficient than that of the farmers who did not. Many researchers reported that the extension work move the inefficient farmers to closer to the frontier (Balcombe et al. 2007; Rahman et al., 2009; Coelli et al., 2003; Rahman, 2003 and Myint and Kyi, 2005).However, Coelli et al. (2002) concluded that farmers' age, education, experience; extension and training do not have large influence on efficiency level. So, it can be concluded that extension service by training is superior to extension contact. 
Table 7: Tests of hypotheses on the parameters of the technical inefficiency effect model fitted to watermelon

\begin{tabular}{|l|l|l|l|l|l|}
\hline Null Hypothesis & $\begin{array}{l}\text { Log-Likelihood } \\
\text { under } \mathrm{H}_{0}\end{array}$ & $\mathrm{df}^{\mathrm{a}}$ & $\begin{array}{l}\text { Test statistic } \\
(\lambda)^{\mathrm{b}}\end{array}$ & $\begin{array}{l}\text { Critical } \\
\text { value } \\
\left(\chi_{0.05}^{2}\right)\end{array}$ & Decision \\
\hline $\mathrm{H}_{\mathrm{o}}: \gamma=\delta_{0}=\delta_{1}=\ldots=\delta_{10}=0$ & 37.65 & 13 & 29.3 & 22.36 & $\mathrm{Reject}_{0}$ \\
\hline $\mathrm{H}_{\mathrm{o}}: \gamma=0^{\mathrm{c}}$ & 48.37 & 3 & 7.86 & 7.81 & $\mathrm{Reject}_{0}$ \\
\hline $\mathrm{H}_{\mathrm{o}}: \delta_{1}=\delta_{2}=\ldots=\delta_{10}=0$ & 39.71 & 10 & 25.18 & 18.31 & $\mathrm{Reject}_{0}$ \\
\hline $\begin{array}{l}\mathrm{a} \\
\text { degrees of freedom } \lambda=-2\left[\ln \left\{\mathrm{L}\left(\mathrm{H}_{0}\right)\right\}-\ln \left\{\mathrm{L}\left(\mathrm{H}_{1}\right)\right\}\right] \\
{ }^{\mathrm{c}} \gamma=0 \text { indicates that } \sigma_{\mathrm{u}}{ }^{2}=0 \text { and } \delta_{0}=0, \text { so degrees of freedom corresponding to this hypothesis is 3. }\end{array}$ \\
\hline
\end{tabular}

Generalized likelihood-ratio tests of null hypotheses, that the inefficiency effects are absent or that they have simpler distributions, are presented in Table 7. The first null hypothesis, which specifies that the inefficiency effects are absent from the stochastic production frontier model, is strongly rejected. The second null hypothesis, which specifies that the inefficiency effects are not stochastic, is also strongly rejected. Therefore, it can be inferred that inefficiency effects are significantly influenced by one or more socio-economic characteristic of the farmer. The third null hypothesis, considered in Table 7, specifies that the inefficiency effects are not a linear function of the age, education, profession, farming experience, farm size, mode of ownership, extension contact, training, micro credit and watching or listening agricultural programme on TV and/or Radio,. This null hypothesis is also rejected at $5 \%$ level of significance. It indicates that the joint effect of these ten explanatory variables on the inefficiency level of production is significant $(p<0.05)$ though the individual effect of one or more of the variables may not be statistically significant. The inefficiency effects in the stochastic frontier are clearly stochastic and are not unrelated to the age, education, profession farming experience of the farmers, farm size, mode of ownership extension contact, training, micro credit and watching or listening agricultural programme on TV and/or Radio. Thus it appears that the proposed stochastic frontier production function model is a significant improvement over the corresponding stochastic frontier which does not involve a model for the technical inefficiency effects.

\subsection{Farmers' perception on major sources of risk in watermelon farming}

The farmer's perception on major sources of risk was summarized by using Kruskal-Wallis One Way Analysis of Variance (ANOVA) by ranks, the major sources of risk as perceived by the respondents were ranked from 1-6. With 1 and 6 representing the lowest and highest ranked sources of risk, respectively is as shown by Table 8 .

Table 8: Results of Kruskal-Wallis test for major sources of production risk.

\begin{tabular}{|l|l|l|}
\hline Sources & Mean & Rank \\
\hline Damage by diseases, pest, insecticides & 782.48 & 5 \\
\hline Expensive inputs & 507.67 & 4 \\
\hline Natural calamity & 911.02 & 6 \\
\hline Irrigation facility & 436.93 & 3 \\
\hline Credit facility & 335.09 & 2 \\
\hline Others & 269.82 & 1 \\
\hline Chi-square & 614.90 & \\
\hline Degree of freedom & 5 & \\
\hline Asymp. Sig. & 0.000 & \\
\hline
\end{tabular}

Table 8 showed that natural calamity (mean 911.02), damage by disease, pest and insecticides (mean 782.48), expensive inputs (mean 507.67) were the highest ranked sources of production risk as perceived by the respondents while irrigation facility (mean 436.93), credit facility (mean 335.09), others (mean 269.903) were perceived as the lowest ranked sources of production risks by the respondents. The table also showed that all the sources of risk in production of watermelon respondents were significant at all levels and that they are statistically different from one another.

\section{Conclusion}

The study examined the existence of technical inefficiencies in watermelon production of Bangladesh. That is, yield can be considerably improved without increasing the levels of inputs. At full technical efficiency, on an average, the farmers could increase outputs by $14 \%$ without increasing existing input resources. This study also reveals that access to micro-credit and training are the significant factors for reducing technical inefficiency in producing watermelon. So, the government can make an attempt to improve farmer's efficiency for growing watermelon by facilitating easy access to micro credit and organizing training programme by the department of agricultural extension. 


\section{References}

[1]. M. G.Rabbany, A. Rahman, S. Afrin, Hoque and F. Islam, Cost of production of watermelon and profitability at Gopalgonj district in Bangladesh, European journal of Banking and Finance, 10(2), 2013, 102-112.

[2]. G. T. Taylor and Shonkwiler, Alternative stochastic specification of the frontier production function in the analysis of agricultural credit programmemes and technical efficiency, Journal of Development Economics, 21(3), 1986, 149-160.

[3]. M. Ali and J. C. Flinn, Profit efficiency among basmati rice producers in Pakistan's Punjab, American Journal of Agricultural Economics, 71(2), 1989, 303-310.

[4]. K. P. Kalirajan and R. T. Shand, A generalized measure of technical efficiency, Applied Econometrics, 21, 1989 , $25-34$.

[5]. B. E. Bravo-Ureta and R. E. Evenson, Efficiency in agricultural production: The case of peasant farmers in eastern Paraguay, Agricultural Economics, 10(1), 1994, 27-37.

[6]. A. Banik, Technical efficiency of irrigated farms in a village of Bangladesh, Indian Journal of Agricultural Economics, 49(1), 1994, 70-78.

[7]. T. R. Shanmugam and K. Palanisami, Measurement of economic efficiency - frontier function approach, Journal of Indian Society of Agricultural Statistics, 45(2), 1994, 235-242.

[8]. V. P. Sharma and K. K. Datta, Technical efficiency in wheat production on reclaimed alkali soils, Productivity, 38(2), 1997, 334

[9]. K. Thomas and R. Sundaresan, Economic efficiency of rice production in Kerala. The Bihar Journal of Agricultural Marketing, 8(3), 2000, 10-315.

[10]. M. S. Hoque, M. F. Uddin and M. A. Islam, A market model for watermelon with supply under rational expectations: An empirical study on Bangladesh, European Scientific Journal, 11(9), 2015, 236.

[11]. S. Majumder, B. K. Bala, F. M. Arshad, M. A. Haque and M. A. Hossain, Food security through increasing technical efficiency and reducing postharvest losses of rice production systems in Bangladesh, Journal of Food Security, 8, 2016, 361-374.

[12]. M. N. Hasnain, M. E. Hossain and M. K. Islam, Technical efficiency of Boro rice production in Meherpur district of Bangladesh: A stochastic frontier approach, American Journal of Agriculture and Forestry, 3(2), 2015, 31-37.

[13]. K. M. M. Rahman, P. M. Schmitz and T. C. Wronka, Impact of farm-spcific factors on the technical inefficiency of producing rice in Bangladesh, Bangladesh Journal of Agricultural Economics, XXII(2), 1999, 19-41.

[14]. M. R. Islam, M. Hossain and W. M. H. Jaim, Technical efficiency of farm producing transplanted Aman rice in Bangladesh: A comparative study of aromatic fine and coarse varieties, Bangladesh Journal of Agricultural Economics, XXVII (2), $2004,1-24$.

[15]. K. H. Koirala, A. K. Mishra and S. Mohanty, Determinants of rice productivity and technical efficiency in the Philippines. Dept. of Agricultural Economics and Agribusiness, Louisiana State University Baton Rouge, LA 70803, 2014

[16]. M. Z. Haider, M. S. Ahmed and A. Mallick, Technical efficiency of agricultural farms in Khulna, Bangladesh: Stochastic frontier approach, International Journal of Economics and Finance, 3 (3), 2010.

[17]. M. A. Hossain, M. K. Hasan and Q. Naher, Assessment of technical efficiency of potato producers in some selected areas of Bangladesh, Journal of Agricultural Rural Development 6(1\&2), 2008, 113-118.

[18]. M. E. Bakh, and M. S. Islam, Technical and allocative efficiency of growing wheat in northwest districts of Bangladesh, Bangladesh Journal of Agricultural Economics XXVIII (1\&2), 2005, 73-83.

[19]. K. M. M. Rahman, M. A. Quddus and M. E. Haque, Estimation of gross and net technical efficiencies of wheat production in Bangladesh under two alternative functional forms, Bangladesh Journal of Agricultural Economics, XXV(2), 2002, 83-101.

[20]. U. W. Ibrahim, A. S. S. Umar and B. Ahmed, Technical efficiency and its determinants in watermelon production in Borno State, Nigeria, Journal of Economics and Sustainable Development, 5(27), 2014.

[21]. M. Kulekci, Technical efficiency analysis for oilseed sunflower farms: A case study in Erzurum, Turkey, Journal of Science Food and Agriculture, 90(9), 2010, 1508-1512.

[22]. M. J. Farrell, The measurment of production efficiency, Journal of the Royal Statistical Society, Series A, 120(3), 1957, 253-281.

[23]. T. J. Coelli, D. S. P. Rao, C. J. O’Donnell and G. E. Battese, An introduction to efficiency and productivity analysis. $2^{\text {nd }}$ ed., Spinger, USA. 10(2), 2005, 241-261.

[24]. D. J. Aigner, C. A. K. Lovell and P. Schmidt, Formulation and estimation of stochastic frontier production function models, Journal of Econometrics, 6(1), 1977, 21-37.

[25]. W. Meeusen and V. D. J. Broeck, Efficiency estimation from Cobb-Douglas production function with composed error term, International Economic Review, 18(2), 1977, 435-444.

[26]. G. E. Battese and G. S. Corra, Estimation of a production frontier model: With application to the pastoral zone of eastern Australia. Australian Journal of Agricultural Economics, 21(3), 1977, 169-179.

[27]. G. E. Battese and T. J. Coelli, A model for technical inefficiency effects in a stochastic frontier production function for panel data. Empirical Economics, 20, 1995, 325-332.

[28]. M.Kulekci, Technical efficiency analysis for oilseed sunflower Farms: A case study in Erzurum, Turkey, Journal of Food Science and Agriculture, 90(9), 2010, 1508-1512.

[29]. T. J. Coelli, A Guide to FRONTIER Version 4.1: A computer program for stochastic frontier production and cost function estimation. CEPA working papers No. 7/96. Department of Econometrics: University of New England, Armidalr, 1996.

[30]. D. A. Kodde and F. C. Palm, 'Wald criteria for jointly testing equality and inequality restrictions: notes and comments, Econometrica, 54(5), 1986, 1243-1248.

[31]. K. P. Kalirajan and J. C. Flinn, The measurement of farm-specific technical efficiency. Pakistan Journal of Applied Economics, II (2), 1983, 167-180.

[32]. S. B. Fakayode, M. A. Y. Rahji and S. T. Adeniyi, Economic analysis of risks in fruits and vegetables farming in Osun state, Nigeria, Bangladesh Journal of Agricultural. Research, 37(3), 2012, 473-491.

[33]. D. W. Wayne, Applied Non-parametric Statistics. Second edition, (PNS-Kent Publishing company, Boston, 1990), 225-226.

[34]. J. N. Binam, J. Tonye, N. Wandji, G. Nyambi and M. Akoa, Factors affecting the technical efficiency among smallholder farmers in the slash and burn agriculture zone of Cameroon. Food Policy, 29(5), 2004, 531-545.

[35]. M. Bozoglu and V. Ceyhan, Measuring the technical efficiency and exploring the efficiency determinants of vegetable farms in Samsun Province, Turkey. Agricultural systems, 94(3), 2007, 649-656.

[36]. B. K. Bala, M. A. Haque, S. Majumder and A. Hossain, Post-harvest loss and technical efficiency of rice, wheat and maize production systems: Assessment and measures for strengthening food security, Final Technical Report (CF-8), Department of Farm Power and Machinery, Bangladesh Agricultural University, Mymensingh-2202. 2009.

[37]. M. A. Alam, Productivity, profitability and efficiency of producing fish in Bangladesh. M. S. Thesis, Department of Agricultural Statistics, Bangladesh Agricultural University, Mymensingh, Bangladesh, 2005.

[38]. K. Balcombe, I. Fraser, M. Rahman and L. Smith, Examining technical efficiency of rice producers in Bangladesh, Journal of International Development, 19(1), 2007, 1-16. 
[39]. S. Rahman, A. Wiboonpongse, S. Ssiboonchitta and Y. Chaovanapoonphol, Production efficiency of Jasmine rice producers in northern and north-eastern Thailand, Journal of Agricultural Economics, 53(3), 2009, 607-626.

[40]. T. Coelli, S. Rahman and C. Thirtle, A stochastic frontier approach to total factor productivity measurement in Bangladesh, Journal of International Development, 15(3), 2003, 321-333.

[41]. S.Rahman, Profit efficiency among Bangladeshi rice farmers, Food Policy, 28(5), 2003, 487-503.

[42]. T. Myint and T. Kyi, Analysis of technical efficiency ofiIrrigated rice production system in Myanmar. Conference on International Agricultural Research for Development, Suttgart-Hohenheim, Germany, 2005.

[43]. T. Coelli, S. Rahman and C. Thirtle, Technical, allocative, cost and scale efficiencies in Bangladesh rice cultivation: A nonparametric approach, Journal of International Development, 53, 2002, 607-626. 